\title{
Discrimination of Commercial Roasted and Ground Coffees According to Chemical Composition
}

\author{
Romilaine M. N. de Souza and Marta T. Benassi* \\ Departamento de Ciência e Tecnologia de Alimentos, Universidade Estadual de Londrina, \\ CP 6001, 86051-970 Londrina-PR, Brazil
}

\begin{abstract}
Cafés torrados e moídos comerciais (38 amostras) e cafés com espécie conhecida (arábica e robusta) foram caracterizados por análise de componentes principais, utilizando-se como variáveis, ácido nicotínico, trigonelina, ácido 5-o-cafeoilquínico (5-CQA), cafeína, caveol e cafestol, potencialmente indicadoras das espécies. O estudo objetivou avaliar a importância desses parâmetros na discriminação entre cafés. Ácido nicotínico foi eficiente na caracterização da torra. Trigonelina e 5-CQA destacaram-se pela variabilidade, tanto entre as amostras puras, como nos cafés comerciais. O maior potencial de discriminação entre as espécies foi atribuído aos parâmetros termoestáveis (cafeína, caveol e cafestol). No geral, maiores teores de cafeína e menores de diterpenos (caveol e cafestol) foram relacionados a proporções de robusta mais elevadas no produto, constatando-se uma tendência de diminuição na razão caveol/cafestol e aumento na razão cafeína/caveol. Esses dois novos parâmetros (razões caveol/cafestol e cafeína/caveol) foram propostos como ferramentas para avaliação da adição de robusta em cafés comerciais.
\end{abstract}

Roasted and ground 38 commercial coffees and coffees of known species (arabica, robusta) were characterized by principal component analysis using as variables nicotinic acid, trigonelline, 5-o-caffeoylquinic acid (5-CQA), caffeine, kahweol and cafestol, which are potentially indicative of species. The objective of the study was to assess the relevance of such parameters in coffee discrimination. Nicotinic acid allowed the characterization of roasting degree. Trigonelline and 5-CQA presented variability among arabica and robusta coffees as well as among commercial ones. Thermostable parameters (caffeine, kahweol and cafestol) had high discriminative potential between the species. In general, high levels of caffeine and low levels of diterpenes (kahweol and cafestol) were related with higher proportions of robusta in the products, which were observed by the decreasing kahweol/cafestol ratio and increasing caffeine/kahweol ratio. The use of these new parameters (kahweol/cafestol and caffeine/kahweol ratios) was suggested as tools for assessing the addition of robusta in commercial coffees.

Keywords: arabica, robusta, pca, kahweol/cafestol, caffeine/kahweol

\section{Introduction}

Coffee is one of the main food commodities in the worldwide economy, and it is the most consumed beverage after tea. ${ }^{1}$ Brazil is the world leader in the production and exportation of coffee ${ }^{2}$ because Brazil is a heavy producer of both Coffea arabica (arabica) and Coffea canephora (robusta) species. ${ }^{3}$ Arabica and robusta coffees differ considerably in price, sensorial quality and acceptance. ${ }^{2,4}$ In general, arabica coffee has a higher concentration of carbohydrates, lipids and trigonelline in the green and roasted products, providing a superior sensorial cup quality,

*e-mail: martatb@uel.br and robusta coffee has high levels of caffeine.$^{5-8}$ Conversely, robusta coffee is widely accepted in market due to its low cost, and it is considerably used in blends with arabica. ${ }^{2}$ In Brazil, more than $80 \%$ of the commercial roasted coffee are blends of the C. arabica and C. canephora species, which offer a low cost product and a beverage adjusted to the preference or habits of consumers. ${ }^{2,4}$ The Brazilian legislation provides criteria for coffee quality classification with indicated proportions of robusta used in the blends. ${ }^{9}$

The green beans of $C$. arabica and $C$. canephora have different colors, shapes and sizes. After roasting and grinding, however, such species cannot be visually distinguished, which is why it is necessary to use chemical parameters for their discrimination. As they belong to 
the same genus, arabica and robusta coffees have little differences in their compositions. There is no consensus on which compounds should be employed for detecting the addition of the lower value robusta coffee to arabica coffee in commercial blends. ${ }^{10}$

Several components could be used as indicators or discriminators for the arabica and robusta species. However, their concentrations generally depend not only on the species but also on the geographic origin, presence of defective beans and roasting degree. This variability and the large amount of compounds studied require the use of multivariate statistical techniques, such as principal component analysis (PCA), to assess the data. Chemical constituents proposed as possible discriminators include water-soluble (caffeine, trigonelline, nicotinic and chlorogenic acids) $)^{11-14}$ and fat-soluble compounds (kahweol and cafestol). ${ }^{7,15,16}$

Caffeine is stable to the roasting process. The highest caffeine contents have been reported for robusta coffee and coffees with small proportions of defective grains. . $^{611,13,14,17-21}$ The roasting process promotes the degradation of trigonelline and chlorogenic acid (CGA), ${ }^{19,22}$ causing variation in their concentrations depending on the presence and on the type of defective beans present. ${ }^{20,23}$ Higher levels of trigonelline and nicotinic acid (product of the trigonelline degradation) have been reported for roasted arabica coffee, and higher levels of CGAs have been reported for roasted robusta coffee. ${ }^{11,14,17,18,24}$

Cafestol is present in both species. However, kahweol has been reported to be specific to arabica coffees. ${ }^{8,14,16,25}$ Furthermore, diterpenes present relative stability to heat treatment, and their levels are only slightly affected by the presence of defective grains. ${ }^{16}$

The quantitative determination of such compounds in commercial blends allowed us to assess the importance and viability of these compounds as a tool for identifying species in different blends of roasted coffee. ${ }^{11,14,16,26,27}$ Hence, the aim of this work was to characterize roasted and ground commercial coffees (38 samples) and coffees of known species (arabica and robusta) through multivariate analysis using compositional variables (nicotinic acid, trigonelline, 5-o-caffeoylquinic acid (5-CQA), caffeine, kahweol and cafestol) and assessing the importance of such parameters in the discrimination of coffee products.

\section{Experimental}

\section{Samples}

Commercial roasted and ground coffees (38 samples) acquired from the local market or supplied by industries were studied. Twenty-three brands from 13 industries associated to the Brazilian Coffee Industry Association (ABIC) were assessed. All samples were sifted through a $0.84 \mathrm{~mm}$ mesh for standardization. The samples were commercialized under different denominations as follows: tradicional (traditional), forte (strong), extra forte (extra strong), gourmet, premium, aralto (high altitude), exportação (export) and espresso (express). Despite the denomination, all coffees presented lightness between 19 and 21 indicating a medium/dark roast degree. Based on the labeling information, only five of the coffees (less than $1 \%$ ) contained only arabica coffee (gourmet), and the other samples had the possibility of an addition of robusta up to $30 \%$ according to the Brazilian legislation. ${ }^{9}$

Pure samples of arabica (A) and robusta (R) coffees were used as references for the comparison with the commercial products. They were provided by the Café Iguaçu Company (Cornélio Procópio-PR, Brazil) and Instituto Agronômico do Paraná (IAPAR, Londrina-PR, Brazil). The coffee beans had distinct geographic origins and different quality levels, which resulted in high heterogeneity among the samples. The R1 and R2 robusta coffees were from Rondônia and Espírito Santo States, respectively, and R1 had higher number of defective beans than R2. R3 was classified as a type 4 coffee according to official data. ${ }^{28}$ The A1 arabica coffee from Minas Gerais State had less defects than A2, which was from Paraná State. The following three arabica coffees of known varieties were also studied: A3 (IAPAR-59), A4 (Catuaí) and A5 (Mundo Novo). The coffees were processed to achieve a roasting degree similar to commercial samples (Table 4). The samples were packed in plastic bags and were stored at $10{ }^{\circ} \mathrm{C}$ until analyses (color, moisture, water-soluble compounds and fat-soluble compounds), which were performed in duplicate.

\section{Chromatographic analysis}

Potassium hydroxide (Vetec, Rio de Janeiro, Brazil), tert-butyl methyl ether (Acrós Organics, NJ, USA) of analytical grade, acetonitrile (J. T. Baker, USA) and acetic acid (J. T. Baker, USA) of chromatographic grade were used as solvents for the extraction and preparation of the mobile phase. The water was obtained from a Milli-Q system (Millipore, USA), and the mobile phases were filtered $(0.45 \mu \mathrm{m}$; Millipore). Analytical grade standards of caffeine (1,3,7-trimethylxanthine; Acrós Organics, NJ, USA), nicotinic acid (n-methylnicotinamide; Vetec, Rio de Janeiro, Brazil), chlorogenic acid (1,3,4,5-tetrahydroxycyclohexane-carboxylic acid; 5-CQA) and trigonelline (1-methylpyridine-3-carboxylate monohydrate; Sigma, Steinhelm, Germany) were 
employed. Kahweol and cafestol standards from Axxora (San Diego, USA) were kept in a freezer at $-18^{\circ} \mathrm{C}$.

The water-soluble compounds were determined by extracting the samples $(0.5000 \mathrm{~g})$ with an acetonitrile:water solution $(5: 95 ; \mathrm{v} / \mathrm{v})$ at $80^{\circ} \mathrm{C}$ for $10 \mathrm{~min}$. The samples were then filtered $(7 \mathrm{~mm})$ into a $100.0 \mathrm{~mL}$ volumetric flask. An aliquot $(5.0 \mathrm{~mL})$ of this solution was transferred to a volumetric flask $(25.0 \mathrm{~mL})$. For the analysis, a Spherisorb ODS- 1 column $(250 \mathrm{~mm} \times 4.6 \mathrm{~mm} ; 5 \mu \mathrm{m})$ (Waters, Milford, USA) and a gradient of $5 \%$ acetic acid and acetonitrile were employed. The detection was carried out at $260 \mathrm{~nm}$ (nicotinic acid and trigonelline), $272 \mathrm{~nm}$ (caffeine) and $320 \mathrm{~nm}$ (5-CQA). ${ }^{26}$

For the fat-soluble compounds, the samples $(0.2000 \mathrm{~g})$ were saponified with $2.0 \mathrm{~mL}$ of $2.5 \mathrm{~mol} \mathrm{~L}^{-1}$ potassium hydroxide (in $96 \%$ ethanol) at $80^{\circ} \mathrm{C}$ for $1 \mathrm{~h}$. After adding $2.0 \mathrm{~mL}$ of distilled water, the unsaponifiable fraction was extracted with $2.0 \mathrm{~mL}$ of tert-butyl methyl ether. This fraction was agitated and centrifuged for $3 \mathrm{~min}$ at $3,000 \mathrm{rpm}$, and the organic phase was collected. The extraction procedure was repeated three times. To clean up, $2.0 \mathrm{~mL}$ of distilled water was added to the extract. After homogenizing and discarding the aqueous phase, the extract was left at $70{ }^{\circ} \mathrm{C}$ until complete dryness. The ether extract was resuspended in $4.0 \mathrm{~mL}$ of mobile phase (55\% acetonitrile in water). The Spherisorb ODS- 1 column with the same specifications as used before and an isocratic elution with an acetonitrile:water solution $(55: 45 ; \mathrm{v} / \mathrm{v})$ were employed. The detection was carried out at $230 \mathrm{~nm}$ and $290 \mathrm{~nm}$ for cafestol and kahweol, respectively. ${ }^{27}$

Before the injection, the samples were filtered $(0.45 \mu \mathrm{m}$; Millipore, USA). The identification of compounds was based on the retention times, UV-Vis (DAD) spectrum and spiking. The quantification was carried out through external standardization with at least five concentrations in triplicate.
For the calculation of the concentrations in dry base, the moisture (g per $100 \mathrm{~g}$ ) was determined $\left(105^{\circ} \mathrm{C}\right.$ for $\left.7 \mathrm{~min}\right)$ using infrared equipment (OHAUS-MB200, USA).

\section{Statistical analysis}

The results were analyzed by principal component analysis (PCA) using Statistica 7.1 software. ${ }^{29}$

\section{Results and Discussion}

Tables 1 and 2 show the contents of water-soluble (nicotinic acid, trigonelline, 5-CQA and caffeine) and fat-soluble (kahweol and cafestol) compounds in the robusta and arabica coffees. The same parameters were individually described for each commercial sample in a preliminary study ${ }^{30}$ and are summarized in Table 3.

The robusta samples (R1, R2 and R3) had the highest contents of caffeine (approximately $2.00 \mathrm{~g}$ per $100 \mathrm{~g}$ ) and lowest levels of cafestol (between 0.19 and $0.24 \mathrm{~g}$ per $100 \mathrm{~g}$ ). Moreover, kahweol was not detected in the robusta samples (Table 1).

The arabica coffees (A1 to A5) had the highest levels of kahweol $(0.82 \mathrm{~g}$ per $100 \mathrm{~g})$ and the lowest concentrations of caffeine (between 1.10 and $1.29 \mathrm{~g}$ per $100 \mathrm{~g}$ ) (Table 2). The caffeine contents were similar to the contents observed for the gourmet coffees (between 0.99 and $1.29 \mathrm{~g}$ per $100 \mathrm{~g}$ ) ${ }^{30}$ and almost half of the caffeine content found in the robusta samples (Table 1).

The behavior observed for the arabica and robusta samples was in accordance with the literature, which describes higher levels of trigonelline and nicotinic acid for arabica coffee..$^{14,17}$ In green and light roasting coffee, 5-CQA is predominant in robusta. ${ }^{11,14,18,24}$ However, as the compound has higher susceptibility to the heat process in

Table 1. Levels of water-soluble and fat-soluble compounds ( $\mathrm{g}$ per $100 \mathrm{~g}$ of sample in dry base) in addition to kahweol/cafestol and caffeine/kahweol ratios found in pure samples of robusta coffee

\begin{tabular}{lcccc}
\hline \multirow{2}{*}{ Parameters } & \multicolumn{3}{c}{ Samples } \\
\cline { 2 - 5 } & R1 & R2 & R3 & Mean \pm SD $(\mathrm{CV} / \%)$ \\
\hline Nicotinic acid & $0.02 \pm 0.00$ & $0.03 \pm 0.00$ & $0.02 \pm 0.00$ & $0.02 \pm 0.00(17)$ \\
Trigonelline & $0.26 \pm 0.01$ & $0.07 \pm 0.00$ & $0.34 \pm 0.01$ & $0.22 \pm 0.14(63)$ \\
5-CQA & $0.24 \pm 0.00$ & $0.04 \pm 0.00$ & $2.04 \pm 0.02$ & $0.21 \pm 0.15(72)$ \\
Caffeine & $2.01 \pm 0.03$ & $1.98 \pm 0.07$ & n.d. & $2.01 \pm 0.03(2)$ \\
Kahweol & n.d. & n.d. & $0.21 \pm 0.01$ & n.d. \\
Cafestol & $0.24 \pm 0.01$ & $0.19 \pm 0.01$ & - & $0.21 \pm 0.03(13)$ \\
Kahweol/Cafestol & - & - & - & - \\
Caffeine/Kahweol & - & - & -
\end{tabular}

${ }^{a}$ Mean of two repetitions \pm standard deviation (SD); CV: coefficient of variation; n.d.: compound not detected under the conditions of analysis; (-): not calculated. 
Table 2. Levels of water-soluble and fat-soluble compounds (g per $100 \mathrm{~g}$ of sample in dry base) ${ }^{\mathrm{a}}$ in addition to the kahweol/cafestol and caffeine/kahweol ratios found in pure samples of arabica coffee

\begin{tabular}{lcccccc}
\hline \multirow{2}{*}{ Parameters } & \multicolumn{9}{c}{ Samples } \\
\cline { 2 - 7 } & A1 & A2 & A3 & A4 & A5 & Mean \pm SD $(\mathrm{CV} / \%)$ \\
\hline Nicotinic acid & $0.03 \pm 0.00$ & $0.04 \pm 0.00$ & $0.03 \pm 0.00$ & $0.03 \pm 0.00$ & $0.02 \pm 0.00$ & $0.03 \pm 0.01(20)$ \\
Trigonelline & $0.40 \pm 0.00$ & $0.19 \pm 0.00$ & $0.71 \pm 0.00$ & $0.52 \pm 0.01$ & $0.64 \pm 0.01$ & $0.49 \pm 0.20(42)$ \\
5-CQA & $0.24 \pm 0.00$ & $0.10 \pm 0.00$ & $0.44 \pm 0.00$ & $0.30 \pm 0.00$ & $0.37 \pm 0.00$ & $0.29 \pm 0.13(46)$ \\
Caffeine & $1.29 \pm 0.01$ & $1.26 \pm 0.01$ & $1.10 \pm 0.01$ & $1.29 \pm 0.01$ & $1.14 \pm 0.00$ & $1.22 \pm 0.09(7)$ \\
Kahweol & $0.80 \pm 0.03$ & $0.66 \pm 0.02$ & $0.93 \pm 0.02$ & $0.89 \pm 0.02$ & $0.82 \pm 0.02$ & $0.82 \pm 0.10(13)$ \\
Cafestol & $0.42 \pm 0.00$ & $0.36 \pm 0.00$ & $0.28 \pm 0.01$ & $0.32 \pm 0.01$ & $0.48 \pm 0.02$ & $0.37 \pm 0.08(21)$ \\
Kahweol/Cafestol & $1.90 \pm 0.07$ & $1.84 \pm 0.04$ & $3.40 \pm 0.10$ & $2.78 \pm 0.02$ & $1.73 \pm 0.04$ & $2.33 \pm 0.73(31)$ \\
Caffeine/Kahweol & $1.61 \pm 0.07$ & $1.91 \pm 0.08$ & $1.18 \pm 0.04$ & $1.45 \pm 0.03$ & $1.39 \pm 0.03$ & $1.51 \pm 0.27(18 \%)$ \\
\hline
\end{tabular}

${ }^{\mathrm{a}}$ Mean of two repetitions \pm standard deviation (SD); CV: coefficient of variation.

Table 3. Levels of water-soluble and fat-soluble compounds ( $100 \mathrm{~g}^{-1}$ of sample in dry base) $)^{\mathrm{a}}$ in addition to kahweol/cafestol and caffeine/kahweol ratios found in commercial roasted and ground coffees

\begin{tabular}{lcc}
\hline Parameters & Mean $\pm \mathrm{SD}(\mathrm{CV} / \%)$ & Range of concentration \\
\hline Nicotinic acid & $0.03 \pm 0.00(15)$ & $0.021-0.038$ \\
Trigonelline & $0.49 \pm 0.17(34)$ & $0.22-0.96$ \\
5-CQA & $0.43 \pm 0.22(50)$ & $0.14-1.20$ \\
Caffeine & $1.47 \pm 0.25(17)$ & $1.00-2.02$ \\
Kahweol & $0.47 \pm 0.20(43)$ & $0.10-0.80$ \\
Cafestol & $0.42 \pm 0.06(15)$ & $0.25-0.55$ \\
Kahweol/Cafestol & $1.07 \pm 0.38(35)$ & $0.27-1.82$ \\
Caffeine/Kahweol & $4.19 \pm 3.29(79)$ & $1.34-20.07$ \\
\hline
\end{tabular}

${ }^{a}$ Mean \pm standard deviation (SD) of 38 samples; CV: coefficient of variation; individual values for each product previously described by De Souza et al. ${ }^{30}$

the robusta matrix, higher contents of 5-CQA is observed in dark roast arabica coffee..$^{14,31}$ Robusta coffee has higher levels of caffeine, lower levels of cafestol and an absence of kahweol when compared to arabica coffee. , $8,11,13,14,16-19,25^{-1}$

Considering that each brand can adopt a different blend, the differences among the raw material, especially the species employed (arabica and robusta), in addition to the differences of the roasting degrees and defects, generated variability between the samples for all compounds studied. The parameters that had less variation among the products were caffeine, nicotinic acid and cafestol with a coefficient of variation $(\mathrm{CV})$ less than $20 \%$. Trigonelline, kahweol and 5-CQA were highly varied among the products (CV from 34 to 50\%) (Table 3). Trigonelline and 5-CQA, however, had wide variability even among the pure species: CV from 63 to $72 \%$ for robusta (Table 1) and from 42 to $46 \%$ for arabica (Table 2). Thus, it was not possible to attribute the variability of these compounds only to the variation between the species because even a slight change in the roasting process could result in an expressive variation of some of the compounds.

Principal component analysis (PCA) was employed to assess the discrimination capability of the following variables: nicotinic acid, trigonelline, 5-CQA, caffeine, kahweol and cafestol (Figure 1). The first two principal components (PC) accounted for $71 \%$ of the variance observed (Figure 1). Equations 1 and 2 were obtained by the loadings of the PCs, and they generated the coordinates of the principal component graphic (Figure 1b).

$$
\begin{aligned}
\text { PC1 }= & 0.102 \text { nicotinic }+0.480 \text { trigonelline }+ \\
& 0.411 \text { chlorogenic }-0.462 \text { caffeine }+ \\
& 0.465 \text { kahweol }+0.401 \text { cafestol }
\end{aligned}
$$

$$
\begin{aligned}
\text { PC2 }= & 0.640 \text { nicotinic }-0.383 \text { trigonelline }- \\
& 0.486 \text { chlorogenic }-0.329 \text { caffeine }+ \\
& 0.310 \text { kahweol }+0.056 \text { cafestol }
\end{aligned}
$$

The main parameters of PC1 were as follows: caffeine (negative correlation), and cafestol, kahweol, 5-CQA and trigonelline (positive correlation) (Figure 1a). Nicotinic acid (positive correlation) was the parameter of more relevance in PC2. Trigonelline and 5-CQA (negative correlation) also contributed to PC2. Thus, there was evidence that $\mathrm{PC} 1$ was associated with the raw material employed, because PC1 was correlated with compounds that presented a large variability among the species (Tables 1 and 2). Considering the correlation of PC2 with compounds formed (nicotinic acid) or degraded (5-CQA and trigonelline) in the roasting process, $\mathrm{PC} 2$ contributed to the roasting characterization.

In general, the coffees were within a medium/dark roasting range, which was indicated by the values of 

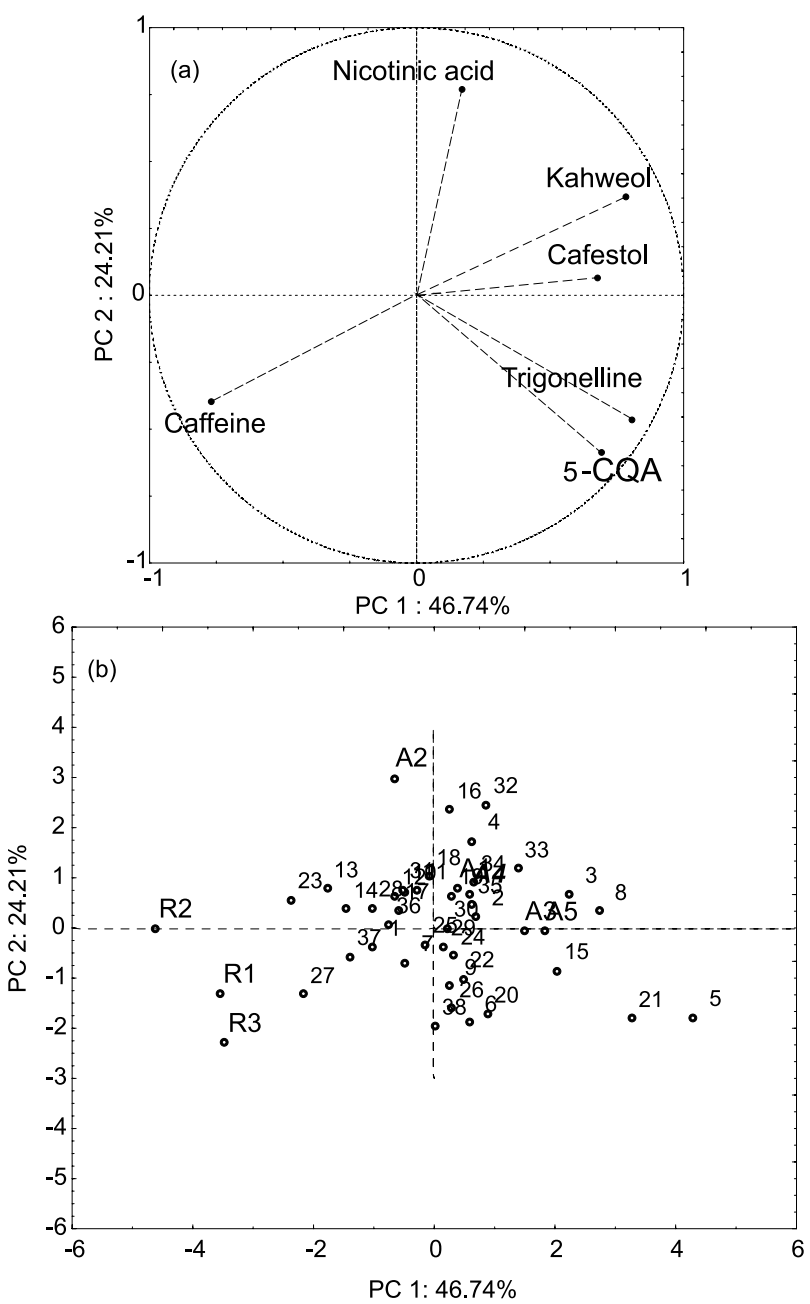

Figure 1. Projection of the variables (a) and samples (b) in the principal components (PC1 and PC2). R1, R2 and R3 (robusta); A1, A2, A3, A4 and A5 (arabica); numbers 1 to 38 (commercial samples).

color $\left(\mathrm{L}^{*}\right.$ and $\left.\mathrm{H}^{*}\right)$ and weight loss percentage estimated according to Dias ${ }^{14}$ (Table 4).

Samples that are configured on the top of the graphic in Figure $1 b$ had higher levels of nicotinic acid and lower concentrations of 5-CQA and trigonelline as compared to the other coffees, indicating a more aggressive roasting

Table 4. Roasting assessment of commercial, arabica and robusta coffees expressed as weight loss percentage (WL\%) and parameters of color (lightness, $\mathrm{L}^{*}$, and hue, $\left.\mathrm{H}^{*}\right)^{\mathrm{b}}$

\begin{tabular}{lccc}
\hline \multirow{2}{*}{ Parameters } & \multicolumn{3}{c}{ Samples } \\
\cline { 2 - 4 } & Commercial & Arabica & Robusta \\
\hline L $^{*}$ & $20.28 \pm 1.87$ & $16.26 \pm 2.68$ & $17.97 \pm 3.79$ \\
$\mathrm{H}^{*}$ & $54.88 \pm 2.49$ & $51.56 \pm 2.17$ & $57.27 \pm 1.89$ \\
WL\% & $15.91 \pm 1.53$ & $16.32 \pm 2.15$ & $18.48 \pm 1.90$ \\
\hline
\end{tabular}

astimated according to the following equation: WL\% $=26.81-12.12$ SUM (nicotinic acid + trigonelline) + 4.26 RATIO (5-CQA/caffeine) $0.13 \mathrm{~L}^{*}-0.06 \mathrm{H}^{*}\left(\right.$ Dias $\left.^{14}\right)$; ${ }^{\mathrm{b}}$ mean \pm standard deviation of 38 commercial coffees, 5 arabica coffees and 3 robusta coffees. process. For example, there were estimated weight losses of 17 and $18 \%$ for samples 32 and 16, respectively, according to Table S1 (Supplementary Information (SI)). Samples, such as coffees 20 and 38, which are located on the bottom of the graphic in Figure 1b, had a 14\% weight loss indicating a light roasting degree (Table S1 in the SI section).

Considering PC1, samples shown on the right side of the graphic in Figure 1b had higher levels of diterpenes (kahweol and cafestol), 5-CQA and trigonelline and a lower concentration of caffeine as compared to the other coffees. The standard arabica coffees (A1, A2, A3, A4 and A5) and the gourmet samples (3, 5, 15, 21 and 35) were placed in this region, which was characteristic of arabica coffee, and these coffee samples had a different behavior from the other samples. ${ }^{30}$

In general, the pure samples were separated into the following two groups: (i) robusta coffee and (ii) arabica coffee. The blended samples were well distributed in the intermediate space where the upper right region was reserved for samples close to arabica coffee and the lower left region for those close to robusta coffee. The robusta coffees were better grouped and separated from the other samples. The arabica coffees had varied characteristics, which indicated that differences not associated with the species (variety, soil factors, climate factors, defects and roasting process) influenced the samples composition, hindering a more accurate species characterization.

Taking into account that the roasting process was poorly differentiated (Table 4) and assessing the projection of the variables, samples configuration (Figure 1) and the data shown in Tables 1, 2 and 3, it was concluded that the commercial coffee with a high proportion of $C$. arabica species should have high levels of diterpenes (notably kahweol), trigonelline and 5-CQA. Therefore, the addition of robusta coffee to the product should decrease the levels of such compounds and raise the level of caffeine. The highest concentrations of diterpenes, trigonelline and 5-CQA and the lowest concentration of caffeine found in the gourmet samples indicated a higher probability for the presence of pure arabica coffee. The low levels of such compounds, which have also been observed in some traditional samples, ${ }^{30}$ could be attributed to different proportions of robusta coffee in the products.

Considering studies that have applied multivariate techniques to discriminate species, some were limited to the assessment of green coffees ${ }^{32}$ or to pure species. ${ }^{33}$ Working with roasted coffees, some authors have characterized caffeine, trigonelline, 5-CQA ${ }^{11,13,14}$ and kahweol ${ }^{11,14}$ as variables responsible for the separation of species and blends. According to Casal et al. ${ }^{13}$ nicotinic acid does 
not have significant importance in the distinction between the species. Dias ${ }^{14}$ has reported that nicotinic acid and trigonelline can be used for the discrimination of species for samples with light and dark roasting degrees but not with samples of medium roasting degree. In general, higher levels of caffeine and lower levels of kahweol, trigonelline and 5-CQA were related to elevated proportions of robusta. Importantly, these studies were carried out with coffees of known origin, and a comparison among the standard and commercial samples was not found in the literature.

The use of models to estimate the percentage of robusta coffee (R\%) added to arabica coffee has been reported in the literature. Dias ${ }^{14}$ proposed the use of multilinear models for water-soluble compounds and color parameters $\left(\mathrm{R} \%=-209.30+3.94 \mathrm{H}^{*}-102.55\right.$ trigonelline + 59.39 caffeine), and Campanha ${ }^{16}$ proposed the use of models for kahweol and cafestol in dark roasting coffee $(\mathrm{R} \%=73.8106-0.1638$ kahweol +0.1092 cafestol $)$.

These models were applied to the studied commercialized samples (traditional and gourmet) for assessing the probable proportion of robusta coffee. In order to observe the efficiency of the models, they were also applied to arabica and robusta coffees. The best results were observed for samples of $100 \%$ robusta coffee, which had a mean estimative of robusta coffee between 97 and $113 \%$. A huge variability of results and low concordance among the models were shown for arabica coffees, which presented since negative values $(-20 \%)$ in the estimative based on diterpene content until positive values $(16 \%)$ in the model based on the water-soluble compounds (Table 5).

Although considering the possibility of underestimation and overestimation of the values and the error in each modeling, the gourmet coffees, which should be comprised of only arabica species, ${ }^{9}$ had low percentages of robusta coffee in both models (7 and 8\%, Table 5). Concerning the traditional coffees, both models predicted a high mean percentage of robusta $(50 \%)$, which was above the limit allowed by the legislation (30\%). ${ }^{9}$

Depending on the composition of the samples, the models were more or less consistent. Regarding coffee samples 23 and 27, which were placed close to the robusta species in the PCA graphic (Figure 1b), higher percentages of robusta coffee were estimated by both models (between 82 and 98\%). These two samples had low levels of kahweol (0.19 and $0.10 \mathrm{~g}$ per $100 \mathrm{~g}$, respectively) and high concentrations of caffeine ( 1.79 and $2.02 \mathrm{~g}$ per $100 \mathrm{~g}$, respectively), effectively showing a similar behavior to robusta coffees (Table 1) and no similarity with a profile of arabica coffee (Table 2). On the other hand, for coffee samples 29, 30 and 31, which were placed at the center of the PCA graphic (Figure 1b), low values in the Dias ${ }^{14}$ model ( $\mathrm{R} \%$ from -15 to $11 \%$ ) and high values in the Campanha ${ }^{16}$ model (R\% from 67 to $80 \%$ ) were observed. Such divergence occurred because these samples had both low levels of caffeine (between 1.05 and $1.19 \mathrm{~g}$ per $100 \mathrm{~g}$ ) and kahweol (between 0.13 and $0.27 \mathrm{~g}$ per $100 \mathrm{~g}$ ). ${ }^{30}$ These samples did not present a typical profile of either robusta or arabica coffee (Tables 1 and 2), indicating a possible addition of an adulterant different of robusta coffee. Thus, models that separately study the water-soluble and fat-soluble variables may not be efficient to determine the percentages of robusta coffee in commercial samples because of the possible addition of other adulterants to the coffee blends.

In the present study, trigonelline and 5-CQA were relevant parameters in $\mathrm{PC} 1$, but they had the highest variability in commercial (Table 3 ), pure arabica and pure robusta samples (Tables 1 and 2). These parameters may be correlated with the variation among the species. However, they may also be associated with other changes, such as the roasting, processing and the presence of defective beans. Thus, parameters less sensitive to roasting (caffeine, kahweol and cafestol) presented the highest potential of discrimination among the samples.

Considering that water-soluble (caffeine) and fat-soluble compounds (kahweol and cafestol) are among the most important variables in species discrimination and that the models previously mentioned ${ }^{14,16}$ were restricted in the estimation of robusta in commercial coffees due to the separate use of the water-soluble and fat-soluble variables, we proposed the use of combined parameters. The use of relations between such fat-soluble and water-

Table 5. Assessment of the percentage of robusta coffee ( $\mathrm{R} \%)^{\mathrm{a}}$ in commercial (traditional and gourmet), arabica and robusta coffees by the mathematical models proposed by Dias ${ }^{14}$ and Campanha ${ }^{16}$

\begin{tabular}{lcccc}
\hline \multirow{2}{*}{ Models } & \multicolumn{3}{c}{ Samples } \\
\cline { 2 - 5 } & Traditional & Gourmet & Arabica & Robusta \\
\hline Dias $^{14 \mathrm{~b}}$ & $49 \pm 27(-15-93)$ & $8 \pm 14(-2-32)$ & $16 \pm 20(-7-43)$ & $113 \pm 5(109-119)$ \\
Campanha $^{16 \mathrm{c}}$ & $50 \pm 25(-4-98)$ & $7 \pm 15(-7-32)$ & $-20 \pm 22(-47-5)$ & $97 \pm 3(95-100)$ \\
\hline
\end{tabular}

a Mean \pm standard deviation of 33 traditional coffees, 5 gourmet coffees, 5 arabica coffees and 3 robusta coffees; bestimated according to the following equation: $\mathrm{R} \%=-209.30+3.94 \mathrm{H}^{*}-102.55$ trigonelline +59.39 caffeine; cestimated according to the following equation: $\mathrm{R} \%=73.8106-0.1638$ kahweol + 0.1092 cafestol. 
soluble variables (kahweol/cafestol and caffeine/kahweol), proposed by the first time in the literature, would allow a more broad detection of differences.

In this study, the concentrations ranged from 1.10 to $1.29 \mathrm{~g}$ per $100 \mathrm{~g}$ for caffeine, from 0.66 to $0.93 \mathrm{~g}$ per $100 \mathrm{~g}$ for kahweol and from 0.28 to $0.48 \mathrm{~g}$ per $100 \mathrm{~g}$ for cafestol featuring a tipical arabica coffee. It corresponded to a $\mathrm{kahweol} / \mathrm{cafestol}$ ratio $(\mathrm{ka} / \mathrm{ca})$ variation from 1.73 to 3.40 and a caffeine/kahweol ratio (caf/ka) variation from 1.18 to 1.91 (Table 2). Based on these data and previous reports ${ }^{14,16,34}$ regarding the variability in coffee composition, a ka/ca ratio above 1.00 is indicative of arabica coffee. Regarding the caf/ka ratio, values between 1.00 and 3.00 are indicative of arabica coffee, and caf/ka values greater than 4.00 are indicative of robusta coffee. Thus, the addition of robusta coffee should decrease the ka/ca ratio and increase the caf/ka ratio. In addition to robusta coffee, the addition of other adulterants (e.g., maize or husk) or even the presence of defects would result in a decrease in the correlation between caffeine and kahweol. However, the correlation between kahweol and cafestol should remain unchanged because diterpenes are exclusive to coffee and do not present variation with defect levels. ${ }^{16}$

A large variability for the ratios was observed in the commercial products. The $\mathrm{ka} / \mathrm{ca}$ ratios were between 0.27 and 1.82 (average of $1.07 \pm 0.38 ; \mathrm{CV}$ of $35 \%$ ), and the caf/ka ratios were between 1.34 and 20.07 (average of $4.19 \pm 3.29 ; \mathrm{CV}$ of $79 \%$ ) (Table 3). The gourmet samples were similar to $C$. arabica regarding both ratios $(\mathrm{ka} / \mathrm{ca}$ ratio ranged from 1.21 to 1.74 ; and caf/ka ratio ranged from 1.34 and 2.25). Concerning the traditional coffees, $45 \%$ of samples had a ka/ca ratio below 1.00 and a caf $/ \mathrm{ka}$ ratio close to or above 4.00 indicating the probability of a significant addition of robusta coffee to the product (Table S2 in the SI section).

Samples 23 and $27 \mathrm{ka} / \mathrm{ca}$ ratios of 0.54 and 0.27 , respectively; and caf/ka ratios of 9.37 and 20.07, respectively), which were well-described in the models (Table 5), in addition to samples 29, 30 and 31 (ka/ca ratios ranged from 0.52 to 0.80 ; and caf $/ \mathrm{ka}$ ratios ranged from 3.83 to 9.26), which have not been adjusted, may be associated with robusta coffee addition by applying the proposed ratios (Table S2 in the SI section).

\section{Conclusions}

The assessment using PCA showed the relevance of the composition variables in the identification of coffee species in commercial products. The parameters nicotinic acid, trigonelline, 5-CQA, caffeine, kahweol and cafestol were useful to characterize coffee species. Caffeine and diterpenes presented more potential for discriminate the species due to their relative heat stability, while the other parameters presented interaction with the roasting process. In general, higher levels of caffeine and lower levels of kahweol and cafestol were related with higher proportions of robusta coffee in the product. The addition of robusta coffee to arabica coffee could be observed by the decrease in kahweol/cafestol ratio and increase in caffeine/cafestol ratio. Thus, we suggest the use of these two new parameters (kahweol/cafestol and caffeine/kahweol ratios) as tools for assessing the addition of robusta coffee to commercial products.

\section{Acknowledgments}

The authors would like to acknowledge $\mathrm{CNPq}$ (Conselho Nacional de Desenvolvimento Científico e Tecnológico), Fundação Araucária/Paraná, FAEP/UEL (Fundo de Apoio ao Ensino, Pesquisa e Extensão) and CBP\&D/Café (Consórcio Brasileiro de Pesquisa e Desenvolvimento do Café) for scholarships and financial support.

\section{Supplementary Information}

The estimated data for weight loss (WL\%) in commercial (1 to 38), arabica (A1 to A5) and robusta (R1 to R3) coffees analyzed in the present study are shown in Table S1. The kahweol/cafestol and caffeine/ kahweol ratios for each commercial sample are shown in Table S2. Both of these tables are available free of charge at http://jbcs.sbq.org.br as a PDF file.

\section{References}

1. http://www.finep.gov.br accessed in May 2012; Maeztu, L.; Andreza, S.; Ibáñez, C.; Peña, M. P.; Bello, J.; Cid, C.; J. Agric. Food Chem. 2001, 49, 4743.

2. http://www.abic.com.br accessed in May 2012.

3. http://www.agricultura.gov.br accessed in May 2012.

4. http://www22.sede.embrapa.br/cafe/outros/links.htm accessed in May 2012; http://www.apeda.com accessed in May 2012.

5. De Maria, C. A. B.; Moreira, R. F. A.; Quim. Nova 2004, 27, 586; França, A. S.; Oliveira, L. S.; Borges, M. L.; Vitorino, M. D.; Rev. Bras. Armazen. 2001, Especial Café, 37.

6. Ky, C. L.; Louarn, J.; Dussert, S.; Guyot, B.; Hamon, S.; Noirot, M.; Food Chem. 2001, 75, 223.

7. Lago, R. C. A.; Boletim do CEPPA 2001, 19, 319.

8. Speer, K.; Kölling-Speer, I.; Braz. J. Plant Physiol. 2006, 18, 201.

9. http://extranet.agricultura.gov.br/sislegis-consulta/ consultarLegislacao.do?operacao=visualizar \& id $=18524$ accessed in May 2012. 
10. Alves, R. C.; Casal, S.; Alves, M. R.; Oliveira, M. B.; Food Chem. 2009, 114, 295; González, A. G.; Pablos, F.; Martín, M. J.; León-Camacho, M.; Valdenebro, M. S.; Food Chem. 2001, 73, 93; Amorim, A. C. L.; Hovell, A. M. C.; Pinto, A. C.; Eberlin, M. N.; Arruda, N. P.; Pereira, E. J.; Bizzo, H. R.; Catharino, R. R.; Morais Filho, Z. B.; Rezende, C. M.; J. Braz. Chem. Soc. 2009, 20, 313.

11. Alves, S. T.; http://www.bibliotecadigital.uel.br/ document/?code=vtls000100198 accessed in May 2012.

12. Bicchi, C. P.; Binello, A. E.; Pellegrino, G. M.; Vianni, A. C.; J. Agric. Food Chem. 1995, 43, 1549; Campa, C.; Ballester, J. F.; Doulbeau, S.; Dussert, S.; Hamon, S.; Nairot, M.; Food Chem. 2004, 88, 39; Martín, M. J.; Pablos, F.; González, A. G.; Talanta 1998, 46, 1259.

13. Casal, S.; Oliveira, M. B. P. P.; Alves, M. R.; Ferreira, M. A.; J. Agric. Food Chem. 2000, 48, 3420.

14. Dias, R. C. E.; http://www.bibliotecadigital.uel.br/ document/?code=vtls000108937 accessed in May 2012.

15. Alves, S. T.; Scholz, M. B. S.; Benassi, M. T.; Abstracts of the $8^{\circ}$ Encontro Regional Sul de Ciência e Tecnologia de Alimentos, Curitiba, Brazil, 2003; Speer, K.; Tewis, R.; Montag, A.; Abstracts of the $14^{\circ}$ International Conference on Coffee Science - ASIC, San Francisco, USA, 1991.

16. Campanha, F. G.; http://www.bibliotecadigital.uel.br/ document/?code=vtls000127750 accessed in May 2012; Campanha, F. G.; Dias, R. C. E.; Benassi, M. T.; Coffee Sci. 2010, $5,87$.

17. Casal, S.; Oliveira, M. B.; Ferreira, M. A.; Food Chem. 2000, 68,481 .

18. Daglia, M.; Cuzzoni, M. T.; Decano, C.; J. Agric. Food Chem. 1994, 42, 2273.

19. Moreira, R. F. A.; Trugo, L. C.; De Maria, C. A. B.; Quim. Nova 2000, 23, 195.

20. Ramalakshmi, K.; Kubra, I. R.; Rao, L. J. M.; J. Food Sci. 2007, 72, S333.
21. Vasconcelos, A. L. S.; França, A. S.; Glória, M. B. A.; Mendonça, J. C. F.; Food Chem. 2007, 101, 26.

22. De Maria, C. A. B.; Moreira, R. F. A.; Trugo, L. C.; Quim. Nova 1999, 22, 209.

23. Farah, A.; Donangelo, C. M.; Braz. J. Plant Physiol. 2006, 18, 23; França, A. S.; Mendonça, J. C. F.; Oliveira, S. D.; LWT Food Sci. Technol. 2005, 38, 709.

24. Perrone, D.; Farah, A.; Donangelo, C. M.; De Paulis, T.; Martin, P. R.; Food Chem. 2008, 106, 859.

25. Kurzrock, T.; Speer, K.; Food Rev. Int. 2001, 17, 433; Rubayiza, A. B.; Meurens, M.; J. Agric. Food Chem. 2005, 53, 4654.

26. Alves, S. T.; Dias, R. C. E.; Benassi, M. T.; Scholz, M. B. S.; Quím. Nova 2006, 29, 1164.

27. Dias, R. C. E.; Scholz, M. B. S.; Benassi, M. T.; Abstracts of the $2^{\text {nd }}$ Congresso Brasileiro de Ciência e Tecnologia de Alimentos, Curitiba, Brazil, 2006.

28. http://www.fazenda.mg.gov.br/empresas/conselho_ contribuintes/acordaos/2001/3/ 14973013.pdf accessed in May 2012.

29. StatSoft 7.1; Statistica for Windows: Computer Program Manual; Software Inc.: Tulsa, 2006.

30. De Souza, R. M. N.; Canuto, G. A. B.; Dias, R. C. E.; Benassi, M. T.; Quim. Nova 2010, 33, 885.

31. Trugo, L. C.; Macrae, R.; Food Chem. 1984, 15, 219.

32. Mendonça, J. C. F.; França, A. S.; Oliveira, L. S.; Nunes, M.; Food Chem. 2008, 111, 490.

33. Pizarro, C.; Esteban-Díez, I.; González-Sáiz, J. M.; Anal. Chim. Acta 2007, 585, 266.

34. Kitzberger-Sacoman, C. S.; Scholz, M. B. S.; Pereira, L. F. P.; Vieira, L. G. E.; Sera, T.; Silva, J. B. G. D.; Benassi, M. T.; Abstracts of the $23^{\text {rd }}$ International Conference on Coffee Science-ASIC, Bali, Indonesia, 2010.

Submitted: April 25, 2011

Published online: June 28, 2012 


\title{
Discrimination of Commercial Roasted and Ground Coffees According to Chemical Composition
}

\author{
Romilaine M. N. de Souza and Marta T. Benassi* \\ Departamento de Ciência e Tecnologia de Alimentos, Universidade Estadual de Londrina, \\ CP 6001, 86051-970 Londrina-PR, Brazil
}

Table S1. Estimated data for weight loss (WL\%) in commercial (1 to 38), arabica (A1 to A5) and robusta (R1 to R3) coffees

\begin{tabular}{|c|c|c|}
\hline \multicolumn{2}{|c|}{ Samples } & \multirow{2}{*}{ WL\% } \\
\hline Numbers/letters & Code $^{\mathrm{b}}$ & \\
\hline 1 & $\mathrm{AEF}$ & 16.40 \\
\hline 2 & $\mathrm{BP}$ & 15.45 \\
\hline 3 & BG & 16.79 \\
\hline 4 & $\mathrm{CT}$ & 17.71 \\
\hline 5 & CG & 12.41 \\
\hline 6 & DT & 15.11 \\
\hline 7 & DEF & 16.82 \\
\hline 8 & DA & 14.95 \\
\hline 9 & DEX & 16.12 \\
\hline 10 & ET & 17.58 \\
\hline 11 & $\mathrm{EF}$ & 17.33 \\
\hline 12 & EEF & 17.00 \\
\hline 13 & FT & 18.40 \\
\hline 14 & FEF & 17.38 \\
\hline 15 & FG & 14.29 \\
\hline 16 & GT & 18.18 \\
\hline 17 & HT & 16.77 \\
\hline 18 & $\mathrm{HEF}$ & 17.02 \\
\hline 19 & HP & 16.33 \\
\hline 20 & IEF & 14.23 \\
\hline 21 & IG & 13.11 \\
\hline 22 & JEF & 15.25 \\
\hline 23 & KT & 18.19 \\
\hline
\end{tabular}

\begin{tabular}{|c|c|c|}
\hline \multicolumn{2}{|c|}{ Samples } & \multirow{2}{*}{ WL\% } \\
\hline Numbers/letters & Code $^{b}$ & \\
\hline 24 & LT & 15.66 \\
\hline 25 & MT & 15.83 \\
\hline 26 & NF & 13.90 \\
\hline 27 & OEF & 16.10 \\
\hline 28 & $\mathrm{PF}$ & 16.69 \\
\hline 29 & QT & 13.40 \\
\hline 30 & QEF & 14.87 \\
\hline 31 & REF & 15.01 \\
\hline 32 & SEF & 16.66 \\
\hline 33 & SEF class & 14.35 \\
\hline 34 & $\mathrm{TF}$ & 14.41 \\
\hline 35 & UG & 17.57 \\
\hline 36 & VT & 15.87 \\
\hline 37 & VEF & 17.56 \\
\hline 38 & WES & 14.04 \\
\hline A1 & & 17.43 \\
\hline $\mathrm{A} 2$ & & 19.20 \\
\hline A3 & & 13.52 \\
\hline A4 & & 16.18 \\
\hline A5 & & 15.26 \\
\hline $\mathrm{R} 1$ & & 17.88 \\
\hline $\mathrm{R} 2$ & & 20.60 \\
\hline $\mathrm{R} 3$ & & 16.95 \\
\hline
\end{tabular}

aEstimated according to the following equation: WL\% $=26.81-12.12 \mathrm{SUM}$ (nicotinic acid + trigonelline $)+4.26 \mathrm{RATIO}(5-\mathrm{CQA} / \mathrm{caffeine})-0.13 \mathrm{~L} *-$

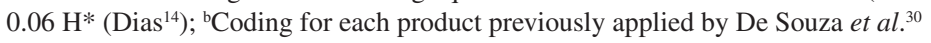


Table S2. Kahweol/cafestol and caffeine/kahweol ratios for commercial coffee samples

\begin{tabular}{|c|c|c|}
\hline Samples & Kahweol/cafestol ratio & Caffeine/kahweol ratio \\
\hline 1 & 0.79 & 5.89 \\
\hline 2 & 1.12 & 2.73 \\
\hline 3 & 1.58 & 1.34 \\
\hline 4 & 1.82 & 1.48 \\
\hline 5 & 1.65 & 1.52 \\
\hline 6 & 0.87 & 4.04 \\
\hline 7 & 0.80 & 4.69 \\
\hline 8 & 1.22 & 1.62 \\
\hline 9 & 0.72 & 4.47 \\
\hline 10 & 0.88 & 3.98 \\
\hline 11 & 1.03 & 3.43 \\
\hline 12 & 0.97 & 3.88 \\
\hline 13 & 0.79 & 5.76 \\
\hline 14 & 0.88 & 5.05 \\
\hline 15 & 1.21 & 2.25 \\
\hline 16 & 1.63 & 1.64 \\
\hline 17 & 1.06 & 3.86 \\
\hline 18 & 1.09 & 3.29 \\
\hline 19 & 1.18 & 2.81 \\
\hline 20 & 1.11 & 2.94 \\
\hline 21 & 1.60 & 1.74 \\
\hline 22 & 0.91 & 3.61 \\
\hline 23 & 0.54 & 9.37 \\
\hline 24 & 1.03 & 3.21 \\
\hline 25 & 0.66 & 6.62 \\
\hline 26 & 1.01 & 3.52 \\
\hline 27 & 0.27 & 20.07 \\
\hline 28 & 0.93 & 4.66 \\
\hline 29 & 0.69 & 6.10 \\
\hline 30 & 0.80 & 3.83 \\
\hline 31 & 0.52 & 9.26 \\
\hline 32 & 1.58 & 1.63 \\
\hline 33 & 1.67 & 1.62 \\
\hline 34 & 1.48 & 2.15 \\
\hline 35 & 1.74 & 1.60 \\
\hline 36 & 1.01 & 4.38 \\
\hline 37 & 0.93 & 4.74 \\
\hline 38 & 0.90 & 4.26 \\
\hline
\end{tabular}

